\title{
ORGANIZATIONAL ADAPTATION TO INTERDEPENDENCE SHIFTS: THE ROLE OF INTEGRATOR STRUCTURES
}

\author{
Mihaela Stan \\ m.stan@ucl.ac.uk \\ UCL School of Management, University College London, \\ 1 Canada Square, London E14 5AB, United Kingdom \\ Phanish Puranam \\ phanish.puranam@insead.edu \\ INSEAD, 1 Ayer Rajah Avenue, Singapore 138676
}

\begin{abstract}
Research summary (113 words):
We investigate how organizational adaptation to interdependence shifts is influenced by "integrators". These are formally mandated managerial roles meant to promote coordination across specialized but interdependent organizational sub-units, yet they do so without relying on formal authority. While much has been learned about how integrators promote steady state coordination within a known pattern of interdependence, less is known about their impact on organizational adaptation when the pattern of interdependence itself is unknown. We discuss mechanisms by which integrators may nonetheless aid organizational adaptation and learning processes in such situations, and test our hypotheses in the context of a regulatory change that affected the IVF clinics sector in the UK using a differences-in-differences design.
\end{abstract}

\section{Managerial summary (115 words):}

Organizational structure can influence how an organization adapts to change. We investigated how a regulatory change in the provision of fertility treatments in the UK forced clinics to change their workflows, and whether the presence of integrator roles enabled clinics to adapt to these changes. It is well known that integrator roles in general are valuable in coordinating across specialized organizational units, but this research points to the surprising implication that their value may persist even when the workflow being coordinated changes suddenly, in ways that nobody necessarily comprehends. Our research highlights the fact that even in an intensively science-based work context, the "technology of organizing" can have a significant role in shaping organizational performance.

Keywords: organizational adaptation, organizational learning, interdependence, organizational design, integrator 


\section{INTRODUCTION}

An important source of heterogeneity in organizational performance lies in the differential ability of organizations to adapt to changes in their environment (Agarwal \& Helfat, 2009; Teece et al. 1997). Significant progress has been made in the use of formal models to understand how organizations may allow limitedly rational individuals to collectively adapt to the complex interdependencies that exist among them (Ethiraj \& Levinthal, 2004; Levinthal and Posen, 2007; Rivkin \& Siggelkow, 2003; Gulati and Puranam, 2009). Such an adaptation process can be challenging even with stable and known patterns of interdependence (Thompson 1967, Malone and Crowston 1994), but is particularly challenging with new and poorly understood patterns of interdependence between actors (Ethiraj and Levinthal 2004, Siggelkow and Rivkin 2005). A theoretical question of interest is thus whether existing organizational structures exacerbate the challenge by locking the organization into previous patterns of interaction that are no longer appropriate, or whether they in fact enable the organization to adapt to new patterns of interdependence.

A key insight from the theoretical literature is that the answer depends on the role that organizational structure can play in ameliorating the dangers of superstitious learning - of drawing misleading conclusions from performance feedback (March and Simon 1958, Levinthal and March 1993). Unknown patterns of interdependence make superstitious learning more likely, because feedback that an individual actor receives contains information not only about the value of one's own actions, but also the actions that others are simultaneously taking (Denrell, Fang and Levinthal, 2003). To the extent that organizational structures prevent or mitigate this effect, they can aid adaptation to changes in interdependence patterns, even when the new pattern is poorly understood 
(Rivkin and Siggelkow, 2003; Ethiraj and Levinthal, 2004; Puranam and Swamy, 2016). Put simply, structure can compensate for the lack of knowledge among its inhabitants, to aid organizational adaptation.

In this study, we move these ideas from the realm of theory to that of empirical analysis. We test a framework that builds on and extends existing theoretical insights about organizational adaptation to shifts in underlying interdependence patterns. Interdependence between agents in an organization exists when the optimal action of one agent is dependent on the actions of another (Thompson, 1967; Puranam et al, 2012). When this changes in a manner such that whether (and how) the agent's actions are interdependent is poorly understood, we say that an "interdependence shift" has occurred. ${ }^{1}$ We study an empirical context in which new regulation produces precisely this kind of change, causing disruption to potentially all organizations that are subject to the regulation. However, we are able to observe stable differences across organizations in a key internal structural feature - formally designated roles called "integrators"- which we expect to aid adaptation to the interdependence shift.

Integrator roles are elements of the formal organizational structure that enable the coordination of efforts across specialized personnel within the organization. These formally mandated managerial roles are meant to enable coordination between (but have limited formal authority over) sets of specialized but interdependent actors (Mintzberg 1979, p.165, Mohrman

\footnotetext{
${ }^{1}$ Such shifts can arise for a variety of reasons: changes in demand conditions Meyer, A. D. (1982). "Adapting to environmental jolts." Administrative science quarterly: 515-537, Adner, R. and D. Levinthal (2001). "Demand heterogeneity and technology evolution: implications for product and process innovation." Management science 47(5): 611-628.; technological change Tushman, M. L. and P. Anderson (1986). "Technological discontinuities and organizational environments." Administrative science quarterly: 439-465, Sosa, M. L. (2011). "From old competence destruction to new competence access: evidence from the comparison of two discontinuities in anticancer drug discovery." Organization Science 22(6): 1500-1516. or regulatory change Aggarwal, V. A. and B. Wu (2015). "Organizational Constraints to Adaptation: Intrafirm Asymmetry in the Locus of Coordination." Ibid. 26(1): 218238.. These shifts may accompany competence destroying or enhancing changes (Tushman and Anderson, 1986), and could underlie architectural or component level changes (Henderson and Clark, 1990). The defining characteristic in each case is the need for adaptation to new and unknown patterns of interdependence among the constituent members of the organization.
} 
1993, p.118). A special case of boundary spanners (Adams 1976, Aldrich and Herker 1977), integrators serve as coordination mechanisms within organizations by ensuring common understanding between functional groups (Mohrman 1993).

Uniquely, we venture beyond arguments of integrator-enabled coordination in steady- state environments to explore the role of integrators in a context involving an interdependence shift. We draw on prior literature to propose that the mechanisms through which integrators normally act, namely the creation of information flows between, and the exercise of informal authority over the individuals whose work they are meant to coordinate, may aid organizational adaptation in the event of an interdependence shift (Lounamaa and March 1987, e.g., Lave and March 1993, Rivkin and Siggelkow 2003, Siggelkow and Rivkin 2005, Levinthal and Posen 2007, Siggelkow and Rivkin 2009, Puranam and Swamy 2013). Crucially, we do not argue that integrators enable organizational adaptation on the basis of superior understanding of the new pattern of interdependence, but rather that they enable the organization to achieve this understanding more rapidly by avoiding superstitious learning (March 1991, Levinthal and March 1993).

We test our arguments in the context of in-vitro fertilization (IVF) clinics in the United Kingdom, which in 2001 experienced a major regulatory change that impacted the patterns of interdependence between the various stages of the IVF process. Clinics varied in whether they already had in place integrator structures to manage the treatment of patients; we could therefore exploit this variation (which could not plausibly be based on anticipated clinic-specific consequences of the regulatory change), to test how effectively they coped with the regulatory change. This is a natural quasi-experiment, with the interdependence pattern in clinics being manipulated through regulatory change (hence "natural"), albeit without random assignment into the use of integrators (hence "quasi-").

The rest of this paper is organized as follows: we first develop our theoretical arguments, 
and then give a detailed description of our context and the regulatory change that occurred, to help map theoretical arguments to empirical operationalization. After a description of data and methods, we report our results, and conclude with a discussion of their implications for theory and practice.

\section{THEORY}

\section{The adverse consequences of an interdependence shift}

Specialization within a system inevitably leads to interdependence in the sense that the specialized parts must eventually work together (March and Simon 1958). Regardless of the basis for dividing organizations into sub-units, interdependence across units is thus ubiquitous in a world of imperfect decomposability (Thompson 1967, Nadler and Tushman 1997, see also Heath and Staudenmayer 2000).

There are well-known challenges associated with organizational learning and adaptation in situations of interdependence. Effective learning requires being able to form valid connections between one's actions and observed outcomes. Interdependence obscures the links between individual actions and outcomes, because the observed outcomes may be the result of the actions of many interdependent actors (March and Simon 1958, Levinthal and March 1993). When the nature of these interdependencies is well understood, then it is possible to account for the impacts of other's actions on the observed outcome; but when it is not, as is the case of a change to a new and unknown interdependence pattern, a serious challenge to organizational learning is posed. The dangers of drawing misleading conclusions from performance feedback (i.e. superstitious learning) are high in such situations because the feedback contains information not only on the value of one's own actions, but also the unobserved actions taken by others (Levinthal \& March, 1993).

An interdependence shift produces exactly this complication. When the pattern of linkages between optimal actions across agents changes in ways that they do not fully comprehend, it 
requires a process of mutual adjustment to find new combinations of actions (Sosa, Eppinger et al. 2004, Sosa, Eppinger et al. 2007). To think about this abstractly, in a two player game, if the conditional payoffs change in an unknown manner, the pattern of their interdependence has changed and we would say an interdependence shift has occurred. More concretely, in a multistage production process, an interdependence shift can be said to have occurred if a) formerly interdependent actions are now independent b) vice versa, or c) the interdependencies between the actions of employees within a stage or across stages change, so that different combinations of their actions are now optimal. ${ }^{2}$ Adapting to the new pattern, and the dangers of superstitious learning that arise in this process, are the source of disruption to organizational performance that we focus on.

\section{Why integrators may aid organizational adaptation to interdependence shifts}

Traditionally, integrators in a static interdependence context provide the effort and possess the information needed to coordinate interdependencies across individuals who may themselves not possess either. Thus, whether we consider project managers (Allen 1984, Wheelwright and Clark 1992); case managers in hospitals (Gittell, 2002); vehicle-integration managers (Iansiti and Clark 1994, Loch, Pich et al. 2001) or account managers in large, multiple-service banks (de la Torre, Martinez Peria et al. 2010), in each case we see integrators managing interdependencies that are in principle well understood, but which the functional grouping structure of the organization leaves unmanaged. Integrators are thus a classic instance of a linking mechanism (Nadler \& Tushman, 1997), and they operate by being channels of information flow (e.g. Allen, 1984) as well as through the exercise of informal authority (Wheelwright and Clark 1992,

\footnotetext{
${ }^{2}$ The essentially dichotomous nature of the representation of interdependence in Design Structure Matrices usually makes it hard to show the third type of change we note here. We thank an anonymous referee for helping us see this.
} 
Mohrman 1993, p.118).

An interdependence shift, by definition implies that none may truly know the new pattern of interdependence between functional units; how then can an integrator be useful? Indeed, one possibility to consider is that structural elements of organizations may in fact impede organizational adaptation by acting as constraints on the actions of the individuals they are meant to coordinate. This is an argument that plays a central role in notions of organizational inertia (Hannan and Freeman 1984, p. 154).

However, we believe that integrators are somewhat distinctive in their nature as elements of organizational structure. Our arguments draw on the two well-documented features of how integrators function (e.g., Allen 1984, Wheelwright and Clark 1992, Mohrman 1993, Gittell 2001).

First, integrators provide a channel for information flow that allows for coordinated adaptation. A shift in the pattern of interdependence between agents requires them to find new patterns of mutually consistent ways of working, which preserve or even increase overall performance. The challenge of doing so is great when each specialist makes independent choices that are not visible to others; but through their common presence across stages, integrators may be able to keep interacting specialists better informed of each other's actions. By their nature, integrators occupy multiple "thought worlds" (Dougherty 1992), and are able to communicate and keep informed the individuals they link about the actions and intentions of each other.

Integrators thus act much as team scaffolds do in medical care contexts (Edmondson and Valentine, 2015). Team scaffolds are structures that bound sets of roles given shared responsibility for a focal task, and allow for continuity in round-the-clock staffing of medical personnel. This can lead to significant improvement in patient throughput time despite the lack of stable team composition. Moreover, the dangers of overspecialization when disruptions to 
collective learning occur can be overcome by scaffolds which ensure that learning from different sources and at different levels is mutually reinforcing (Anderson and Lewis 2014, p. 373). The role of integrators as channels of communication, we argue, should be similar, reducing the likelihood of superstitious learning (Lounamaa \& March, 1987; March, 1991; Levinthal and March, 1993; Lave and March, 1993).

Second, integrators, through the exercise of informal authority may be able to control the rates of adaptation of those they coordinate. Informal authority arises from expertise, prestige and status, and is not necessarily aligned with formal decision rights within an organization. For instance, Clark and Wheelwright (1992) noted that integrators in some industries are often chosen for the role because they were "heavy weights" - had sufficient prestige and clout, to exercise some degree of authority that was formally not theirs to exercise. This informal authority, we argue, can be very effective in adapting to unknown interdependence patterns, because both too rapid and too slow learning by individuals is problematic in such contexts (Lounamaa and March 1987, Puranam and Swamy 2013). Integrators may slow down (without stopping) rates of individual change through their exercise of informal authority. While they may lack the formal authority to overrule or veto other's decisions, their informal authority may nonetheless partially constrain the actions of those they coordinate, as they may question, discourage and seek justification (particularly for actions that may appear to have local benefits but global costs) on the basis of their "heavy weight" attributes. By slowing down (rather than stopping) changes, the informal authority exercised by integrator roles may thus help to aid adaptation to interdependence shifts.

In sum, existing theory suggests that integrator structures can help improve coordinated learning (and suppress superstitious learning) following an interdependence shift, which should allow organizations that employ them to learn about the new pattern of interdependence (and recover their performance) faster than organizations that do not have such structures. Integrators 
can achieve this result by enabling a mutually aware set of responses by acting as information channels, as well as by keeping individual learning rates away from the extremes, thus improving combined learning rates. For these reasons, we expect that:

Hypothesis 1: Following an interdependence shift, the use of integrator structures enable organizations to mitigate the adverse performance consequences of the shift.

Hypothesis 1 does not allow for a distinct test of the two mechanisms through which integrators function (as channels of information and informal authority). While we know that integrators in general operate on the basis of their ability to provide channels of communication as well as exercise informal authority, it is unlikely that all integrators exercise both aspects equally. For instance, not all integrators are heavy-weight (Clark and Wheelwright, 1992), nor do all function equally effectively as communication channels (Gittell, 2002). The differences in the extent to which integrators are able to draw on both these mechanisms should translate into meaningful differences in their effectiveness. Specifically, we expect that:

Hypothesis 2: Following an interdependence shift, integrator structures that can draw on both mechanisms (i.e. informal authority and communication channels) should enable organizations to mitigate the adverse performance consequences of the shift more effectively than integrator structures that use only one of these mechanisms.

\section{EMPIRICAL CONTEXT: REGULATION-INDUCED SHIFTS IN INTERDEPENDENCE FOR UK FERTILITY CLINICS}


Regulatory changes, by altering the nature of legally compliant work, can alter interdependencies in organizations (Agarwal and Wu, 2015). While fertility treatments performed before 2001 in the U.K. allowed for three or more embryos to be transferred to a patient in order to increase the chance of pregnancy, a regulatory intervention in this year required clinics to transfer at most two embryos to patients, with single-embryo transfers strongly recommended for women up to the age of 35 (HFEA 2001). These restrictions on the embryo count - which is a critical input for fertility treatments - prompted IVF clinics to compensate for the decline in the treatment effectiveness through various measures, thus altering the nature of the interaction between specialists involved in IVF (see Figure 1 for the decreasing trend of embryo use after 2001).

To understand the impact of this change, we conducted a total of 19 face-to-face interviews with doctors, nurses and administrators in the industry. For a separate set of eighteen respondents, we elicited job descriptions for integrators in the IVF field by contacting (via email or telephone) both clinics using integrators as well as clinics not using them. We also reviewed published articles on the management and organizational processes of such clinics.

\section{---- Insert Figures $1 a$ and $1 b$ here ----}

The task of performing IVF consists of several stages (i.e., ovarian stimulation, egg extraction, gamete manipulation, and embryo transfer), and requires the joint participation of medical personnel coming from several areas of specialization: fertility doctors, embryologists, lab technicians and nurse specialists. Figure 2 summarizes the sequence of interventions needed to achieve an IVF pregnancy. To highlight the differences between pre- and post-change configuration of actions, as evidenced from our field data, we note the most typical reported adjustments in each box. 
To understand the challenges of achieving coordinated action among these specialists, it is important to note that IVF continues to be a treatment with modest success rates, ${ }^{3}$ and that many biological, physiological and clinical variables confound the outcomes of interventions along the treatment trajectory. While an understanding of the biological and physiological uncertainties in IVF are beyond the aims of this research, the coordination challenges resulting from interdependent specialists having to adapt to a new pattern of interaction are the focus of this study.

The most obvious consequence of restricting the number of embryos used after 2001 was the need to change lab technologies. As outputs of micro-manipulations performed in the lab, embryos resulting from fertilization began to receive greater attention than before. Two major developments in lab technology have taken place in response to embryo count restrictions: morphological scoring of embryos to ensure that the embryos selected for transfer are also the most viable (Baczkowski, Kurzawa et al. 2004), and extending in-vitro embryo development until the stage of blastocyst, which is a more developed embryo with a higher chance of implantation (Papanikolaou, Kolibianakis et al. 2008).

With these changes to the technologies of embryo selection and embryo development, activities in other stages had to change as well, but in ways that had to be discovered rather than known upfront. As one doctor we interviewed put it, "when the freedom to use as many embryos as we found appropriate was taken away, we began to ask different questions than before (...) and sometimes to do things in a different order". For example, downstream from the lab, it was found that transfers of blastocysts had to occur later and required more sophisticated culture

\footnotetext{
${ }^{3}$ Currently, the theoretical likelihood of achieving a live-birth in one IVF cycle is estimated to be in the $20-30 \%$ range, which is close to the "natural" success rate in healthy patients.
} 
mediums and equipment, as well as closer monitoring of the patient's womb prior to embryo transfer compared to the pre-change regime. Moreover, upstream from the lab, during the stage of egg collection and handling, it was found that adjustments to surgery procedures and biological culture conditions also had to be made to ensure better selection and greater developmental potential for the fertilized eggs.

To be clear, cross-stage dependencies always existed in IVF: drugs regimens for inducing ovulation do not impact just the egg count, but also egg quality and womb functioning, with rippling effects for later stages in the treatment. Cross-stage dependencies also existed after the regulatory change. However, our argument is not about a change in the levels of steady state interdependence before and after the regulatory change. Rather, our point is that when the regulatory change imposed a sudden limit on inputs or options for one stage, the pattern of interaction across stages had to adapt to take this into account- to discover new combinations of choices across stages that would lead to good outcomes. Thus not only "component", but also "architectural" changes (Henderson and Clark 1990) in IVF provision were sharply triggered by the regulatory change in 2001.

The challenges to organizational adaptation were thus very real in our empirical setting. In IVF treatments the final outcome is the result of a series of interdependent actions taken by different individuals at different stages. This leads to difficulties in attributing the success or failure of the IVF treatment to an action in the overall sequence, which is compounded after an interdependence shift, when the manner in which these actions are interdependent is no longer understood.

\section{Integrator roles in IVF clinics}

As crucial points of discontinuity, the moments when health-care workers hand-over patients to one another involve communication about the patient and/or the transfer of responsibility for the 
patient (Solet, Norvell et al. 2005, Briscoe 2007, Cohen and Hilligoss 2010). Our fieldwork revealed that in IVF the organizational arrangements employed for organizing clinic resources around an individual patient fall into two broad categories: relying only on standardized procedures for patient handoff; or using in addition a specific individual (doctor or nurse) to set the treatment course and to intervene for patient-specific adjustments (see also Gittell, Hagigi et al. 2009). These individuals in our framework are integrators and have objectives very similar to “case managers" (Gittell 2002) or "nurse coordinators" (Daft, Murphy et al. 2009, p. 108), and were in existence since the entry of the clinics into our observation window, before the regulatory change in 2001.

Our field and interview notes corroborate that the primary purpose of the integrators is to ensure smooth hand-overs between stages, and to improve the quality of the patient experience. Moreover, our informants agreed that these roles have been employed mostly by clinics using a patient-centered approach to care, and that the job descriptions tend to be all-inclusive in terms of contingencies that the integrator should be prepared to address during the fertility treatment.

In the IVF clinic context, while both nurses and doctors can play the role of integrators, and have the same broad objectives, it is generally recognized that doctors and nurses do not discharge their roles in the same way (Savage 1995, Baumann, Deber et al. 1998, Wicks 1998, McGarvey, Chambers et al. 2000). Doctor-integrators are generally known to exercise stronger informal authority than nurses (Tucker, Edmondson et al. 2002, p.129, Edmondson 2003, p.1424), while nurse-integrators add a layer of informational richness and ease of communication with and about the patient which is superior to that of doctor-integrators (Nembhard and Edmondson 2006, p.943).

These differences have led the medical management literature to refer to two normative models - 'care' vs. 'cure', with the cure model having been associated with physicians, and the 
care model with nursing and other allied health professionals (Baumann, Deber et al. 1998, Wicks 1998). Our interviews in the field reinforced the impression that doctor-integrators and nurse-integrators work quite differently from each other. Nurses in general have limited prescribing power, are less forceful in their interactions, are more inhibited by protocols, and are less expected to take responsibility for the errors of others (than doctors). On the other hand, nurses are more likely to have social connection and "soft skills" in lateral communication across teams, as well as at translating technical terms and coaching junior staff members (see Table 2 for details).

---- Insert Table 2 here ----

If we accept the premise that each kind of integrator has a relative advantage at one of the two ways in which an integrator functions - through providing a communication channel, and through exercising informal authority, then Figure 3 illustrates how these integrator arrangements may differ along the dimensions of informal authority and lateral communication.

---- Insert Figure 3 here ----

Clinics able to provide either type of integrator arrangement (i.e. either nurse- or doctorintegrator at patient level) allow both types of influence - strong informal authority and strong lateral communication on behalf of the patient - to co-exist under the same roof and to reinforce each other, (albeit not at the same time for every patient, but across patients). Consequently, the professionals being coordinated alternately by nurses and doctors may experience spillovers between the experiences. When working with a nurse-coordinator, they may improve knowledge sharing across specializations; when working with a doctor, they may more readily make local concessions for global benefits. But to the extent these knowledge benefits or willingness to adapt survive beyond the current patient and transfers to the next, there are effectively spillovers across patients. Consequently, clinics that can make available either type of integrator should be 
able to benefit more from these spillovers, leading to better performance, as we argued in Hypothesis 2.

In, sum, the IVF setting and our comprehensive data have several advantages for testing the relationship between integrator roles and organizational adaptation to interdependence shifts. First, there is a well-established and widely agreed upon measure of success: the rates of success of IVF treatment at the clinic (i.e. births per patient). Second, because published Annual Patient Guides contain information on whether a clinic offers the service of a "patient liaison" (i.e. integrator) we can access reliable data on the existence of the integrator role in IVF clinics. Finally, and most importantly, this setting provides a quasi-experimental design which helps to rule out some alternative explanations about the impact of integrators by observing clinics before and after the restrictions placed on the number of embryo transfers in 2001.

With the entire population of clinics being subjected concomitantly to the same regulatory change which led to an interdependence shift, we can pinpoint the effect of having an integrator separately from the possibility that the decision to have an integrator was made because of the change. Thus, the regulatory change serves two purposes for our empirical analysis that regular business as usual conditions cannot fulfill: it changes the interdependence that underlies the production process within our clinics (so that any knowledge advantage that integrators may have had in terms of understanding the patterns of interdependence would no longer hold), and the existence of the integrator structure in a clinic is unlikely to have been in anticipation of this change. We can thus compare differences between clinics with and without integrators, before and after the regulatory change (a "differences-in-differences" design), on the premises that there are no time-varying unobserved variables that are correlated with a clinic having an integrator and with clinic performance, and that there are no time invariant sources of heterogeneity that are correlated perfectly with having an integrator. These premises seem plausible since having an 
integrator is itself time invariant in our data, and could not possibly have been anticipative of the regulatory change. Further, all time invariant unobserved heterogeneity that may be less than perfectly correlated with having an integrator can be controlled for with clinic fixed effects.

\section{Method}

Sample and Data. In the United Kingdom, data on all IVF centers have been collected and published by the Human Fertilisation and Embryology Authority (HFEA), which is the independent regulator that oversees the use of gametes and embryos in infertility treatment and research in the UK. By applying to the HFEA under the terms of the Freedom of Information Act, we were able to access past data on variables such as success rates, integrator roles and patient mix for the population of all fertility clinics based in the UK since 1991 - the year prior to the introduction of IVF as an authorized treatment - and up to 2006 (the final year for which data were made available).

We obtained data for all the 98 IVF clinics in the UK, which had at least two consecutive years of performance data between 1992 and 2006. We screened out 28 clinics which did not have continuous data for the five-year time window before and after the regulatory change of 2001 (i.e., years 1999 to 2003 inclusively), either because they ceased their operations before $2001(\mathrm{~N}=13)$ or because they were founded after $1999(\mathrm{~N}=10)$. In the three years following the change, 7 exited the IVF domain (5 in 2002), and only one of them had an integrator. Since our analysis requires data for a clinic both before and after the regulatory change, these had to be eliminated, and we recognize this can pose a conservative bias on the estimates of the effect of integrators in adapting to an interdependence shift. A test of the differences between the excluded clinics and the 70 clinics remaining in the sample reveals that those excluded were on average younger, smaller and had less cumulative experience; also, clinics that ceased their operations 
before the change window had lower success rates, while those founded after the regulatory change had higher success rates than those in the sample. While these differences are significant, the exclusion of these clinics is necessary because they do not meet the important criterion for useful inclusion in our study, of having to cope with the regulatory change. Summary statistics for the characteristics of the clinics in our final sample are presented in Table 3.

\section{---- Insert Table 3 here ----}

While the proportion of clinics reporting the use of integrators is similar for both the excluded clinics and those that remained in the sample (i.e., approximately 50\%), almost none of the clinics have changed their integrator status throughout the duration of observation. From the remaining 70 clinics, none have adopted the integrator at a later stage, after operating without an integrator from its inception; however, three clinics which used integrators since founding did cease to report using them after 2004. To guard against confounding effects due to the change in the integrator status, we remove from the sample those clinic-year observations that occurred after these clinics implemented the change, and we keep the rest of their clinic-year observations because they still allow for a reasonable post-change observation of at least two years. We contacted the three clinics which stopped reporting the use of integrators to verify that the decision to discontinue with the integrator could not be linked to the regulatory change of 2001.

In sum, for the 70 clinics in our unbalanced panel there are 914 clinic-year observations, a minimum of 6 years of observation per clinic, and an average of 13.1 years of observation per clinic. More importantly, all clinics in our sample had to undergo fundamental changes in their clinical processes to cope with the regulatory restrictions on embryos, without changing their integrator status throughout the period of observation. Thus, because the integrator status is stable for all clinics and predates the regulatory change, the effect of using an integrator cannot be attributed to reactions to the change. While there may be clinic-level unobserved attributes that 
correlate with using integrators (and also with how clinics fare in response to the regulatory change), we are able to control for clinic fixed effects, which capture such attributes, besides control variables that capture time varying attributes of clinics. Our design however cannot separate out the effects of unobserved properties of clinics that correlate strongly with the use of integrators and influence adaptation to the interdependence shift in the same way that integrators do.

Dependent variable. The main measure of operational performance that allows for crossclinic comparisons in IVF is the rate of success in each clinic. We calculated the measure success rate as the ratio of live-births resulting from IVF treatment done at the focal clinic, divided by the total number of female patients who had IVF treatments at the focal clinic in year $\mathrm{t}$. This measure does not discriminate between singleton, twin or multiple births and is a standard measure to assess clinical performance in this field (Stan and Vermeulen, 2012).

Independent variables. To identify which clinics offered integrators, we used the Annual Patient Guides to IVF (HFEA 2004). If the clinic reported the availability of a "patient liaison" during treatment, the variable integrator was coded as 1; if no liaison role for the patient was reported, integrator was coded as 0 . This measure is used to test hypothesis 1.

Integrator mix. From 1999, the reporting terminology in the patient guides allows us to distinguish between integrator roles filled by doctors (i.e., "one physician throughout treatment") and integrator roles filled by nurses (i.e., "named nurse system"). Thus, if only the option of a dedicated physician was reported, authority-focused integrator was coded as 1 and 0 otherwise; similarly, if only the option of a named nurse was reported, communication-focused integrator was coded as 1 and 0 otherwise. Finally, if both options of a dedicated physician and a named nurse were reported, the measure integrator mix was coded as 1 and zero otherwise. 
Regulatory change. The 2001 policy change was determined by public health considerations regarding the risks of obstetric and neonatal complications following multiple pregnancies, thus placing its occurrence beyond the control of the IVF clinics (HFEA 2001). Indeed, health risks arising from multiple births continue to remain a major concern even after the regulation adopted in 2001, with new regulatory interventions occurring in 2005 and 2008 (HFEA 2005, 2008). To account for the interdependence shift introduced by the regulatory change in IVF, we include a binary variable, post-change, indicating whether the observation occurred after (i.e. equal to 1) or prior to the policy change regarding multiple embryo transfers (i.e. equal to 0) to account for the impact of the change. The interaction term between integrator and post-change $(\mathrm{H} 1)$, and integrator mix and post-change $(\mathrm{H} 2)$ is used to test whether the use of integrators enables or impedes firm-level adaptation to the interdependence shift.

Post-change experience. This is the log transformation of the count measure cumulating the IVF cases treated at the clinic in the years after the regulatory change, lagged by one year (the results are qualitatively the same with zero lags). While this variable takes the value zero prior to the regulatory change, its counterpart pre-change experience takes the value zero after the regulatory change, to reflect how knowledge, skills and structures developed prior to an interdependence shift are supplanted by new knowledge, skills and structures (Darr, Argote et al. 1995, Argote 1999). Because these two measures split the overall experience measure into prechange and post-change experience, the specification of post-change is unnecessary in models accounting for both types of experience.

Control variables. Clinic capacity, measured as the number of patients treated in the year of observation was used as a control for clinic size. As suggested by the medical literature on fertility, which identifies patient age as the most important dimension for characterizing the patient mix of each clinic (Sharif and Afnan 2003 pp. 484, Johnson, El-Toukhy et al. 2007), we 
include a measure accounting for the percent of patients who are 36 years of age or older (complex cases). Finally, to control for the nature of the IVF technology used at the clinic (technology), we include the percent of treatment cycles performed in the current year which involved the more invasive procedure of intra-cytoplasmic sperm injection (ICSI); ICSI is an innovation introduced in the IVF industry during our period of observation, with clinics adopting it at different points in time. The number of years since the clinic was established, clinic age, is included to offset for the lack of data concerning the experience accumulated in the 1980s by nine clinics in the sample which have left censored data. To control for vicarious learning and the state of the art in IVF in each year, we include the measure industry experience, constructed by cumulating all IVF cases treated in the UK prior to the year of observation. To account for improvement in success rates due to overall organizational learning (compared to learning from post-change experience alone), some models include the variable clinic experience constructed by cumulating all IVF patients treated previously at the clinic; in line with prior research (e.g., Argote 1999) we computed the natural log of lagged by one year for all experience measures.

Model specification. Because the data consist of a panel of clinic-year observations, our modeling approach uses linear regression analysis for cross-sectional time-series data. Panel estimation procedures allow us to control for unobserved firm level heterogeneity and thereby reduce the possibility of biased parameter estimates (Greene 2003). The equations used to test the hypothesis have the general form:

$$
w s r_{i, t}=\delta . P S_{t}+\phi P S_{t} . . I_{i}+\beta\left[\text { Controls }_{i, t}\right]+v_{i}+u_{i, t}
$$

Where subscripts refer to firm $\mathrm{i}$ at time $\mathrm{t}, v_{i}=\left(\alpha_{i}+\theta . I_{i}\right), \alpha_{i}$ is the clinic specific unobserved effect, and $u_{i, t}$ is the error term. $w s r_{i, t}$ is the success rate of IVF procedures 
(percentage of women who had live births as a consequence of the treatment) of clinic $i$ in year $t$. $P S_{t}$ is a time varying dummy variable that takes on the value 1 after the change. $I_{i}$ is a clinic specific dummy variable that takes on a value of 1 if the clinic in question has an integrator.

Note that the integrator variable $I_{i}$ does not change over time for a clinic in our sample.

Therefore it is not possible to estimate $\theta$ separately from $\alpha_{i}$ in a fixed-effects estimation- they will be estimated jointly as the firm fixed effect $v_{i}$. However, this does not pose a problem as our theory makes predictions about $\phi$ not $\theta$ (i.e. the interaction term, not the main effect of having an integrator). This inconvenience seems worth bearing as the alternative, a random effects model makes the strong assumption that $v_{i}$ is uncorrelated with the other variables in (1). A Hausman test rejects the hypothesis of random effects in our data $(\mathrm{p}=0.0053)$. We therefore do not consider random effects models as appropriate for our analysis. Note that a disruptive interdependence shift implies that $\delta<0$, and the hypotheses imply $\phi>0 .{ }^{4}$

\section{RESULTS}

Table 3 presents summary statistics for the variables included in our models. Consistent with existing industry analyses, the average IVF success rate for the clinics in our sample is $21 \%$, with nearly half of the clinics employing integrators for IVF cycles. The oldest clinics have been offering IVF for 26 years and the largest clinic had treated over 13,000 patients during the window of observation.

\footnotetext{
${ }^{4}$ To account for the fractional nature of our dependent variable and to check the robustness of our findings, we also replicated our analysis using fractional GLM models (results available from authors on request).
} 
The fixed-effects OLS regressions predicting the success rates in each clinic are reported in Table 4. The estimated clinic fixed effects are significant and provide strong evidence in favor of using panel data techniques which address the problems of correlation between regressors and the time-invariant portion of the error term. The first column in Table 4 reports the results for the control variables and shows that, in general, clinic success rates increase with the age and the cumulative experience of the clinic, and are lower for clinics treating larger proportions of older patients. As expected, the more invasive the IVF technology used the higher the rates of success, further corroborating industry accounts that advances in the micromanipulation of human gametes have played an important role in overcoming the challenges of achieving pregnancies through IVF.

\section{Testing the Hypotheses}

In Table 4 model 2, we introduce the dummy variable post-change, which has a negative coefficient $(\beta=-0.013 ; p=0.087)$. In model 3 , we introduce the interaction between post -change and integrator as a test for hypothesis 1 . In support of $\mathrm{H} 1$, the interaction is positive $(\beta=0.021$; $\mathrm{p}=0.071$ ), and its coefficient of 0.021 is equivalent to a $10 \%$ increase in performance (from a baseline success rate of 21 percentage points). In terms of economic significance, and given that the average clinic has 77 IVF live-births, having an integrator translates into 8 more patients achieving a live birth.

Note however, that the coefficient of the main effect of post-change in model 3 remains negative $(\beta=-0.024 ; p=0.023)$, suggesting that the success rates of clinics without integrators have generally suffered as a result of the embryo restrictions imposed by public legislators. As 
reflected in the size of the coefficient, and given that the average baseline success rate in the sample is $21.5 \%$, the policy change decreased success rates to $19.1 \%$, which is not a trivial effect for a treatment that continues to have a high degree of uncertainty. On the other hand, it appears that the change left the success rates of clinics with integrators effectively unchanged. A statistical test summing the coefficient of the interaction term and that of post-change indicates that the point estimate of 0.003 is not statistically different from zero $(t(69)=-0.29, p=0.769)$. In additional analysis, we found that the effect of the change on clinics without integrators was strongest in the 0-2 year window after the change, and dissipated afterwards, with no difference in performance between clinics with and without integrators thereafter.

To test the robustness of the findings for hypothesis 1 , we also estimated models that included year dummies in addition to controls for industry experience, clinic age and technology. In such models, the post-change dummy is not separately estimated because of collinearity; however the interaction between post-change and integrator can be estimated, and the postchange effect can be obtained by comparing the average effects of the year dummy's before and after the regulatory change. Our results are qualitatively identical with this approach to those reported in the paper.

An additional test of hypothesis 1 is presented in model 5, where we introduce the interaction between the variable integrator and the experience accumulated in the post-change regime, while accounting separately for the experience gained prior to the interdependence shift. The estimated coefficient $(\beta=0.003 ; \mathrm{p}=0.063)$ suggests steeper post-change learning rates for clinics that use integrators.

The tests for hypothesis 2 are reported in models 6-13. Model 6 reports the results from the pooled sub-sample, in which instead of the variable integrator we use three categorical variables: integrator mix, authority-focused and communication-focused integrator setups. The 
results show that the integrator mix significantly improves performance after the interdependence shift, with success rates that are on average 4 percentage points higher than clinics that do not use any integrators, which is the omitted category in Model $6(\beta=0.04, p=0.039)$. However, this coefficient is not statistically different from the other two types of integrators, possibly because in Model 6 we are forcing coefficients to be identical on other variables in the model across the clinics with different kinds of integrators. In models 7, 8 and 9, we present the split sample estimates, in which we compare the coefficient of post-change in three sub-samples: clinics that have an integrator mix, clinics that have only nurse or only doctor integrators, and clinics that don't use integrators. In these split sample analyses, the coefficients of the controls are not constrained to be identical by type of clinic. We find that the coefficient of post-change is significantly higher in clinics with an integrator mix compared to clinics that have only one integrator type $(0.075$ vs. $-0.007, p=0.001)$, as well as compared to clinics that have no integrator at all $(0.075$ vs. $-0.02, \mathrm{p}=0.000)$. Thus, the results provide support for the idea that the integrators act through two different kinds of channels of influence, and that an integrator mix is more valuable than either alone in coping with interdependence shifts.

Models 10 to 13 are an additional test of hypothesis 2, using the measure of post-change experience. Model 10 specifies the interactions between the post-change experience and the binary variables of integrator mix, authority-focused and communication-focused integrator. The interaction between post-change experience and the integrator mix is not statistically significant $(\mathrm{p}=0.110)$ and the coefficient is not significantly different from those of the other two interactions. As with the previous approach for $\mathrm{H} 1$, we present the split-sample analyses for the effect of post-change experience in the subsample of clinics with an integrator mix (models 11), versus clinics with only one type of integrator (model 12) and clinics without integrators (model 13). The results show that the post-change learning rates of clinics that have an integrator mix are 
significantly higher than those of clinics using only one type of integrator (0.012 vs. 0.001 , $\mathrm{p}=0.023)$ and clinics that do not use integrators (0.012 vs. $-0.004, \mathrm{p}=0.0002)$.

\section{Additional analysis}

We conducted three sets of additional analyses to test the robustness of our conclusions about the role of integrators in enabling organizational adaptation.

1. Alternative measure of success: babies/patient. This success measure is similar to our dependent variable in terms of the denominator used (i.e. number of patients) but the numerator counts the total number of babies born through IVF without grouping them into singletons and multiple births. The new measure offers a different way of looking at performance, in which babies rather than births, is the metric of success. The results (which can be found in the online appendix under Table 5) are consistent with those reported in the paper using births/patient as the dependent variable, and have lower levels of $p$-values for the tests of $\mathrm{H} 1$ and $\mathrm{H} 2$ ( $\mathrm{p}=0.024$ and $\mathrm{p}=0.022$ respectively). Because births/patient is the standard measure of performance in the IVF field, we continue to give priority to findings based on this measure (even though babies/patient show stronger results for our hypotheses).

2. Outcomes of intermediate IVF stages. To unpack the black-box of how integrators may have increased the effectiveness of IVF after the regulatory change, and to examine whether our arguments about the value of integrators also allow predictions about the IVF value chain, we obtained intermediate outcome data for three key stages of the IVF process for the whole sample of our data: percentage of cycles achieving egg collection, percentage of cycles with egg collections achieving embryo transfer, and percentage of cycles with embryo transfer achieving implantation. The results (available in the supplementary online material under Table 6) improve our confidence in our theory because they show the negative effect of the constraint on embryo 
transfers, as well as the presence of an integrator improving yields in the subsequent stage of embryo implantation.

3. Patient sorting after the regulatory change. The quasi-experimental design along with our control variables helps to rule out many but not all possible alternative explanations. One important possibility we have to consider is that post-change, patients who were concerned that they were unlikely to conceive under the new regulations restricting the number of embryos transferred, may have selectively dropped out of the IVF market. In particular, if only those candidates who felt they still had good chances opted to go to an IVF clinic that offered an integrator (as a more expensive service feature), then we might observe the pattern of results we do, for reasons unconnected to our theory. One easily observable and reliable indicator by which patients may judge their own chances of conceiving is their own age. If this alternative explanation we have outlined holds, then we should expect that the age mix of patients post-2001 should change, and in particular towards younger patients in clinics with integrators (thus boosting the performance of such clinics post-change). However, in additional analysis (not reported here) we find that the change does not alter the ratio of complex cases (36-year old patients and older) to total cases for clinics with or without integrators, nor for clinics with flexible integrators vs. all other clinics, nor the total number of patients (i.e. there are no difference in differences across clinics with and without integrators, before and after the change). Therefore, a change in patient sorting into clinics with and without integrators after the regulatory change does not plausibly explain our results.

These additional analyses improve our confidence in our findings because the effects of the regulatory change and of the integrator measures are directionally similar, and even stronger in these analyses than in our primary analysis. 


\section{DISCUSSION}

The role that organizational structure plays in organizational adaptation has inspired a recent and growing body of theoretical literature (Rivkin and Siggelkow, 2003; Levinthal \& Posen, 2007; Meyer, Gaba, \& Colwell, 2005; Siggelkow \& Rivkin, 2005; Gulati and Puranam, 2009; Puranam and Swamy, 2016). Yet, the empirical complement to this theorizing has not developed significantly. In this paper, we have taken a step in this direction. We have shown that the use of integratorsmanagerial roles that are mandated to coordinate the contributions of specialized but interdependent agents — enable superior performance in the face of interdependence shifts. This is a novel finding relative to the case of steady state coordination, where the patterns of interdependence are well understood. A key contribution of our study is the finding that integrators may enable more efficient learning from experience (Argote 1999, Argote and Miron-Spektor 2011) in the context of a new pattern of interdependence, even if integrators are just as oblivious as the other task contributors to the new interdependencies brought about by an interdependence shift. Indeed, acting as meso-level structures (Valentine and Edmondson, 2015), integrators help learning processes even if they do not have superior knowledge ab initio about what is being learnt.

Our findings have implications for the literature on organizational design, especially the tradition that examines the relation between organizational structures and adaptive performance. While there has been much progress in terms of identifying correlational effects for various design elements and processes outcomes (Lawrence and Lorsch 1967, Khandwalla 1974, Gittell 2002), as well as theoretically modeling the underlying mechanisms (Levinthal 1997, Levinthal and Warglien 1999, Rivkin and Siggelkow 2003, Ethiraj and Levinthal 2004), empirical evidence has been limited, especially on those features that constitute genuine choices for the management of organizations. The quasi-experimental design of our study establishes a closer-to-causal inference 
about the relationship between organizational structure and adaptation, which improves the identification of the notoriously elusive causal effect of organizational structure on performance.

This study complements prior work that examines differences in the coordination benefits of various integrating mechanisms within an organization. Clark and Wheelwright (1992), for example, draw on their observations of product development teams to contrast "heavyweight" and "lightweight" integrators in terms of level of influence across functional boundaries. In a study of acute-care hospitals, Gittell (2002) found that boundary spanners and team meetings strengthen the reciprocal predictability of action among participants. In a similar vein, Pisano and colleagues (2001) examined the role of feedback activities and cross-functional communication in cardiac surgery and found positive associations with the learning rates of the teams in the study. More recently, Srikanth and Puranam (2011) have assessed the impact of integrative information technologies in the process offshoring, and found that they mitigate the adverse performance consequences of interdependence between onsite and offshore locations.

Distinct from these prior studies, we explored the role of integrators in a context involving an interdependence shift, when the stability of the technological regime is challenged by a disruptive change. We showed that integrators enable organizations to adapt to such shifts. In our analysis, we also documented evidence that is consistent with the theorized impact of the integrator on the underlying processes specific to the IVF technology, as well as for the two mechanisms through which integrators act (information flow and informal authority).

Our focus on organizational adaptation to interdependence shifts is complementary to prior research on organizational learning (Argote 1999, Argote and Ingram 2000, Thompson 2010). In our data, we tested whether or not overall learning rates (i.e. which cumulates experience both before and after the regulatory change) displayed different slopes for clinics using integrators versus those that have not used any type of integrator. We found no evidence for 
such a difference; but indeed found evidence that the performance effect of post-change experience alone is positively moderated by the presence of an integrator (as noted in the tests of $\mathrm{H} 1$ and H2). This suggests that adapting to interdependence shifts and learning within a fixed pattern of interdependence (through learning by doing) may be qualitatively distinct problems, with the integrator more useful in the former.

\section{Limitations}

A significant weakness of this study is that it does not provide direct evidence for the micromechanisms of how integrators help to cope with interdependence shifts- only that they do (and that these effects are visible even at intermediate performance stages). Yet, we believe that the evidence that they do matter is valuable because our results are obtained from a quasiexperimental setting that allows us to rule out many confounding effects.

While we have attempted to overcome many empirical limitations in the analyses, a few remain. Because the data for the study were from a single industry, one potential limitation relates to the generalizability of the findings to other industries. Therefore, although direct generalizability of the study may be limited, we would expect the use of integrator structures to carry adaptive benefits in industries with similar concerns for coordinating efforts across distinct domains of knowledge.

Another potential limitation relates to the regulatory change "hitting" all fertility clinics at the same unanticipated time, but with the use of integrators not randomly assigned — which is what makes our study a quasi-rather than a real experiment (which would feature random assignment). Additionally, the time-invariant measure that captures the presence of integrators as formal elements of structure prevents accurate estimations for the primary effect of the integrator and doesn't account for the possibility that features of this formal arrangement may also evolve over time. In general, our design cannot rule out time varying unobserved factors that may be 
correlated with the time varying effects of integrators on performance. This points to the value of further exploration, namely to account for the more granular details of lateral structures and how they impact organizational adaptation, as well as the possibility of exploiting settings in which there is exogenous variation in integrator structures.

\section{CONCLUSION}

In this paper, we investigate the role of integrators in overcoming the challenges of adapting to an interdependence shift when the nature of interdependence among workers shifts in an unknown way. For empirical corroboration, we investigate the impact of integrators on organizational adaptation in a healthcare domain - the providers of in-vitro fertilization in the UK, using a differences-in-differences design. The analyses indicate that integrators enhance the ability of medical clinics to adapt to this discontinuous change in the industry, measured both in terms of final medical outcomes (successful births), as well as post-change learning curves. We also find support for the idea that, despite the interdependence shift, clinics employing flexible integrator arrangements (i.e., where the role can be filled either by a nurse or a physician) have greater success with their IVF procedures than clinics that use only doctor-integrators or only nurseintegrators. More broadly, our novel results enrich our understanding about the relationship between organizational structure and organizational adaptation, a key theme in the research in strategy. 
Acknowledgements: This research benefited from comments and suggestions made by Srikanth Kannan, Marlo Raveendran, Freek Vermeulen, Bart Vanneste, and seminar audiences at UCL School of Management, National University of Singapore, Seoul National University, Sabanci University, and INSEAD. We are grateful to Sunkee Lee for replicating the statistical analysis.

\section{References}

Adams, J. S. (1976). "The structure and dynamics of behavior in organizational boundary roles." Handbook of industrial and organizational psychology: 1175-1199.

Adner, R. and D. Levinthal (2001). "Demand heterogeneity and technology evolution: implications for product and process innovation." Management science 47(5): 611-628.

Aggarwal, V. A. and B. Wu (2015). "Organizational Constraints to Adaptation: Intrafirm Asymmetry in the Locus of Coordination." Organization Science 26(1): 218-238.

Aldrich, H. and D. Herker (1977). "Boundary spanning roles and organization structure." The Academy of Management Review 2(2): 217-230.

Allen, T. J. (1984). "Managing the flow of technology: Technology transfer and the dissemination of technological information within the R\&D organization." MIT Press Books 1.

Anderson, E. G. and K. Lewis (2014). "A Dynamic Model of Individual and Collective Learning Amid Disruption." Organization Science 25(2): 356-376.

Argote, L. (1999). Organizational Learning: Creating, Retaining and Transferring Knowledge, Kluwer Academic Publishers.

Argote, L. and P. Ingram (2000). "Knowledge transfer: A basis for competitive advantage in firms." Organizational behavior and human decision processes 82(1): 150-169.

Argote, L. and E. Miron-Spektor (2011). "Organizational learning: From experience to knowledge." Organization science 22(5): 11231137.

Baczkowski, T., R. Kurzawa and W. Glabowski (2004). "Methods of embryo scoring in in vitro fertilization." Reproductive biology 4(1): 5-22.

Baumann, A. O., R. B. Deber, B. E. Silverman and C. M. Mallette (1998). "Who cares? Who cures? The ongoing debate in the provision of health care." Journal of Advanced Nursing 28(5): 1040-1045.

Briscoe, F. (2007). "From iron cage to iron shield? How bureaucracy enables temporal flexibility for professional service workers." Organization Science 18(2): 297.

Clark, K. B. and S. C. Wheelwright (1992). "Organizing and leading "heavyweight" development teams." Managing Strategic Innovation And Change: A Collection Of Readings: 419-432.

Cohen, M. D. and P. B. Hilligoss (2010). "The published literature on handoffs in hospitals: deficiencies identified in an extensive review." Quality and Safety in Health Care 19(6): 493.

Daft, R. L., J. Murphy and H. Willmott (2009). Organization theory and design, South-Western Pub.

Darr, E. D., L. Argote and D. Epple (1995). "The acquisition, transfer, and depreciation of knowledge in service organizations: Productivity in franchises." Management science 41(11): 1750-1762.

de la Torre, A., M. S. Martinez Peria and S. L. Schmukler (2010). "Bank involvement with SMEs: Beyond relationship lending." Journal of Banking \&amp; Finance 34(9): 2280-2293.

Dougherty, D. (1992). "Interpretive barriers to successful product innovation in large firms." Organization Science 3(2): $179-202$. 
Edmondson, A. C. (2003). "Speaking up in the operating room: how team leaders promote learning in interdisciplinary action teams." Journal of Management Studies 40(6): 1419-1452.

Ethiraj, S. K. and D. Levinthal (2004). "Bounded Rationality and the Search for Organizational Architecture: An Evolutionary Perspective on the Design of Organizations and Their Evolvability." Administrative Science Quarterly 49(3): 404-437.

Gittell, J. H. (2001). "Supervisory span, relational coordination and flight departure performance: A reassessment of postbureaucracy theory." Organization Science 12(4): 468-483.

Gittell, J. H. (2002). "Coordinating mechanisms in care provider groups: Relational coordination as a mediator and input uncertainty as a moderator of performance effects." Management Science: 1408-1426.

Gittell, J. H., F. Hagigi and D. B. Weinberg (2009). "Modularity and the coordination of complex work: The case of post-surgical patient care." (working paper).

Greene, W. H. (2003). Econometric analysis. New Jersey, Prentice Hall.

Hannan, M. T. and J. Freeman (1984). "Structural inertia and organizational change." American sociological review: 149-164.

Heath, C. and N. Staudenmayer (2000). "Coordination neglect: How lay theories of organizing complicate coordination in organizations." Research in organizational behavior 22: 153-191.

Henderson, R. M. and K. B. Clark (1990). "Architectural innovation: the reconfiguration of existing product technologies and the failure of established firms." Administrative Science Quarterly: 9-30.

HFEA (2001). "HFEA reduces maximum number of embryos transferred in single IVF treatment from three to two " Releases.

HFEA (2004). Patients' Guide to DI and IVF clinics. London, Human Fertilization and Embryology Authority.

lansiti, M. and K. B. Clark (1994). "Integration and dynamic capability: evidence from product development in automobiles and mainframe computers." Industrial and corporate change 3(3): 557-605.

Johnson, A., T. El-Toukhy, S. K. Sunkara, M. Khairy, A. Coomarasamy, C. Ross, S. Bora, Y. Khalaf and P. Braude (2007). "Validity of the in vitro fertilisation league tables: influence of patients' characteristics." BJOG: An International Journal of Obstetrics \& Gynaecology 114(12): 1569-1574.

Khandwalla, P. N. (1974). "Mass output orientation of operations technology and organizational structure." Administrative Science Quarterly: 74-97.

Lave, C. A. and J. G. March (1993). Introduction to models in the social sciences, University Press of America.

Lawrence, P. R. and J. W. Lorsch (1967). "Differentiation and Integration in Complex Organizations." Administrative Science Quarterly 12(1): 1-47.

Levinthal, D. and H. E. Posen (2007). "Myopia of selection: Does organizational adaptation limit the efficacy of population selection?" Administrative Science Quarterly 52(4): 586-620.

Levinthal, D. A. (1997). "Adaptation on rugged landscapes." Management Science: 934-950.

Levinthal, D. A. and J. G. March (1993). "The myopia of learning." Strategic Management Journal 14(S2): 95-112.

Levinthal, D. A. and M. Warglien (1999). "Landscape design: Designing for local action in complex worlds." Organization Science: 342-357.

Loch, C. H., M. T. Pich, C. Terwiesch and M. Urbschat (2001). "Selecting R\&D projects at BMW: A case study of adopting mathematical programming models." Engineering Management, IEEE Transactions on 48(1): 70-80.

Lounamaa, P. H. and J. G. March (1987). "Adaptive coordination of a learning team." Management Science 33(1): 107-123.

Malone, T. W. and K. Crowston (1994). "The interdisciplinary study of coordination." ACM Computing Surveys (CSUR) 26(1): 87119. 
March, J. G. (1991). "Exploration and exploitation in organizational learning." Organization Science 2(1): 71-87.

March, J. G. and H. A. Simon (1958). Organizations, New York: Wiley Press.

McGarvey, H. E., M. G. A. Chambers and J. R. P. Boore (2000). "Development and definition of the role of the operating department nurse: a review." Journal of advanced nursing 32(5): 1092-1100.

Meyer, A. D. (1982). "Adapting to environmental jolts." Administrative science quarterly: 515-537.

Mintzberg, H. (1979). Structuring of organizations: A synthesis of the research, Prentice-Hall.

Mohrman, S. A. (1993). "Integrating roles and structure in the lateral organization." Organizing for the future: The new logic for managing complex organizations 109: 141.

Nadler, D. and M. Tushman (1997). Competing by design: The power of organizational architecture, Oxford University Press.

Nembhard, I. M. and A. C. Edmondson (2006). "Making it safe: The effects of leader inclusiveness and professional status on psychological safety and improvement efforts in health care teams." Journal of Organizational Behavior 27(7): 941-966.

Papanikolaou, E. G., E. M. Kolibianakis, H. Tournaye, C. A. Venetis, H. Fatemi, B. Tarlatzis and P. Devroey (2008). "Live birth rates after transfer of equal number of blastocysts or cleavage-stage embryos in IVF. A systematic review and meta-analysis." Human Reproduction 23(1): 91.

Pisano, G. P., R. M. J. Bohmer and A. C. Edmondson (2001). "Organizational Differences in Rates of Learning: Evidence from the Adoption of Minimally Invasive Cardiac Surgery." Management Science 47(6): 752-768.

Puranam, P. and M. Swamy (2013). "Expeditions without Maps: Learning to Coordinate under Structural Uncertainty." Working paper.

Rivkin, J. W. and N. Siggelkow (2003). "Balancing Search and Stability: Interdependencies among Elements Organizational Design." Management Science: 290-311.

Savage, J. (1995). "Political implications of the named-nurse concept." Nursing times 91(41): 36.

Sharif, K. and M. Afnan (2003). The IVF league tables: time for a reality check, Human Reproduction. 18: 483-485.

Siggelkow, N. and J. W. Rivkin (2005). "Speed and search: Designing organizations for turbulence and complexity." Organization Science 16(2): 101-122.

Siggelkow, N. and J. W. Rivkin (2009). "Hiding the evidence of valid theories: How coupled search processes obscure performance differences among organizations." Administrative Science Quarterly 54(4): 602-634.

Solet, D. J., J. M. Norvell, G. H. Rutan and R. M. Frankel (2005). "Lost in translation: challenges and opportunities in physician-tophysician communication during patient handoffs." Academic Medicine 80(12): 1094.

Sosa, M. E., S. D. Eppinger and C. M. Rowles (2004). "The misalignment of product architecture and organizational structure in complex product development." Management science 50(12): 1674-1689.

Sosa, M. E., S. D. Eppinger and C. M. Rowles (2007). "Are your engineers talking to one another when they should?" Harvard Business Review 85(11): 133.

Sosa, M. L. (2011). "From old competence destruction to new competence access: evidence from the comparison of two discontinuities in anticancer drug discovery." Organization Science 22(6): 1500-1516.

Srikanth, K. and P. Puranam (2011). "Integrating distributed work: comparing task design, communication, and tacit coordination mechanisms." Strategic Management Journal 32(8): 849-875.

Thompson, J. D. (1967). "Organizations in action." New York.

Thompson, P. (2010). "Learning by doing." Handbook of the Economics of Innovation 1: 429-476.

Tucker, A. L., A. C. Edmondson and S. Spear (2002). "When problem solving prevents organizational learning." Journal of Organizational Change Management 15(2): 122-137. 
Tushman, M. L. and P. Anderson (1986). "Technological discontinuities and organizational environments." Administrative science quarterly: 439-465.

Wheelwright, S. C. and K. B. Clark (1992). Chapter 8: Organizing and leading "heavyweight" development teams. New York, Free Press.

Wicks, D. (1998). Nurses and doctors at work: rethinking professional boundaries, Cambridge University Press. 


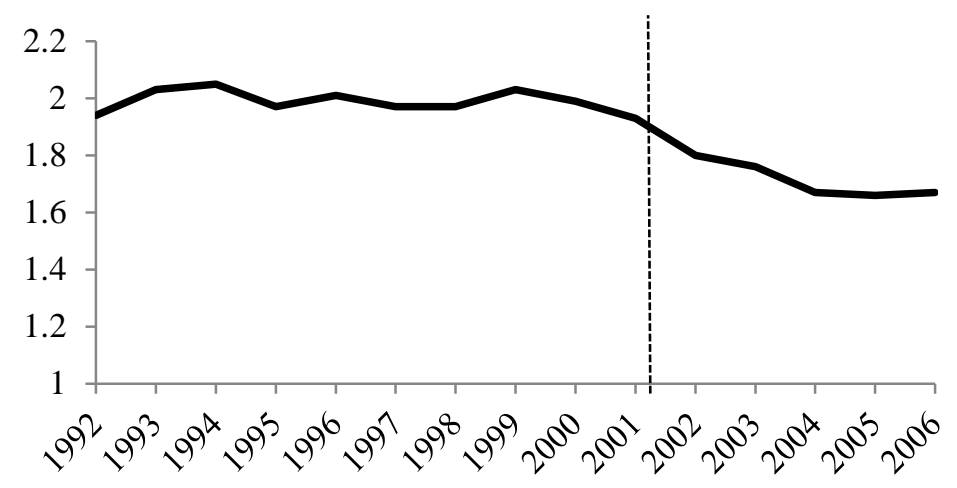

1a) Average number of embryos used in an IVF cycle before and after the regulatory change of 2001

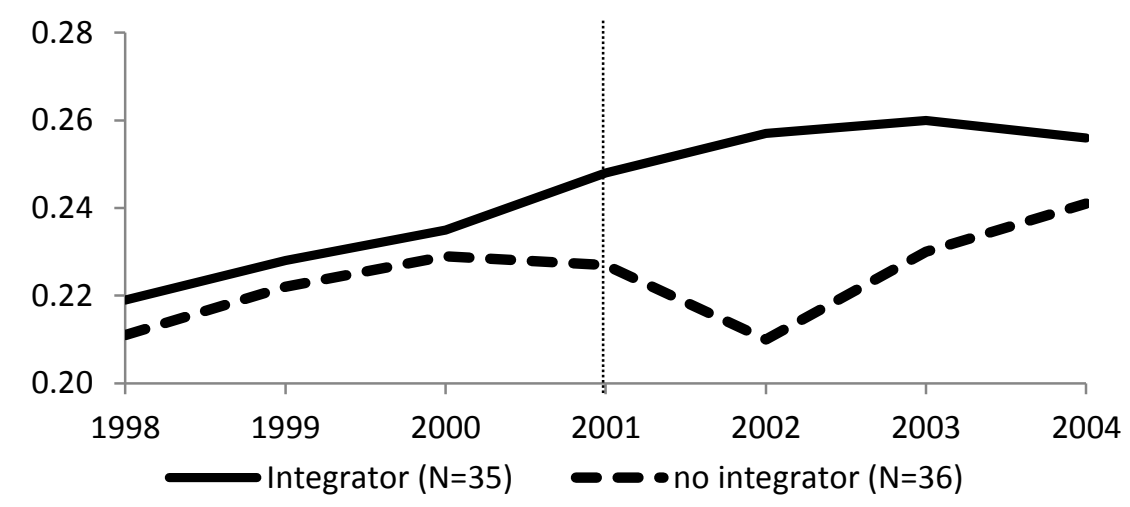

1b) Average success rates in IVF for clinics with- versus without-integrators

Note: $1 \mathrm{a}$ and $1 \mathrm{~b}$ are smoothed graphs, based on raw data, unadjusted for covariates

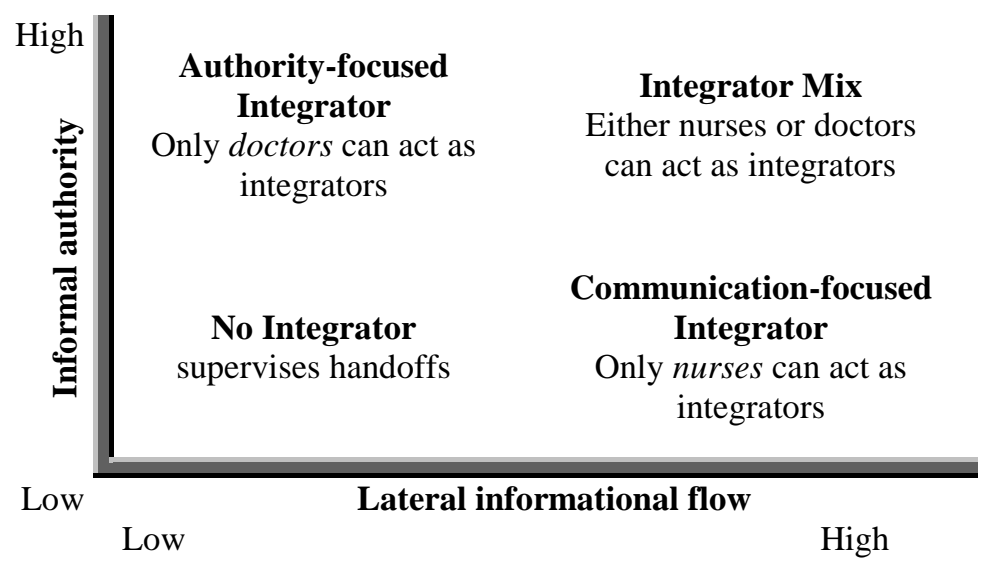

Figure 3. Informal authority and lateral communication for each integrator arrangement in IVF 


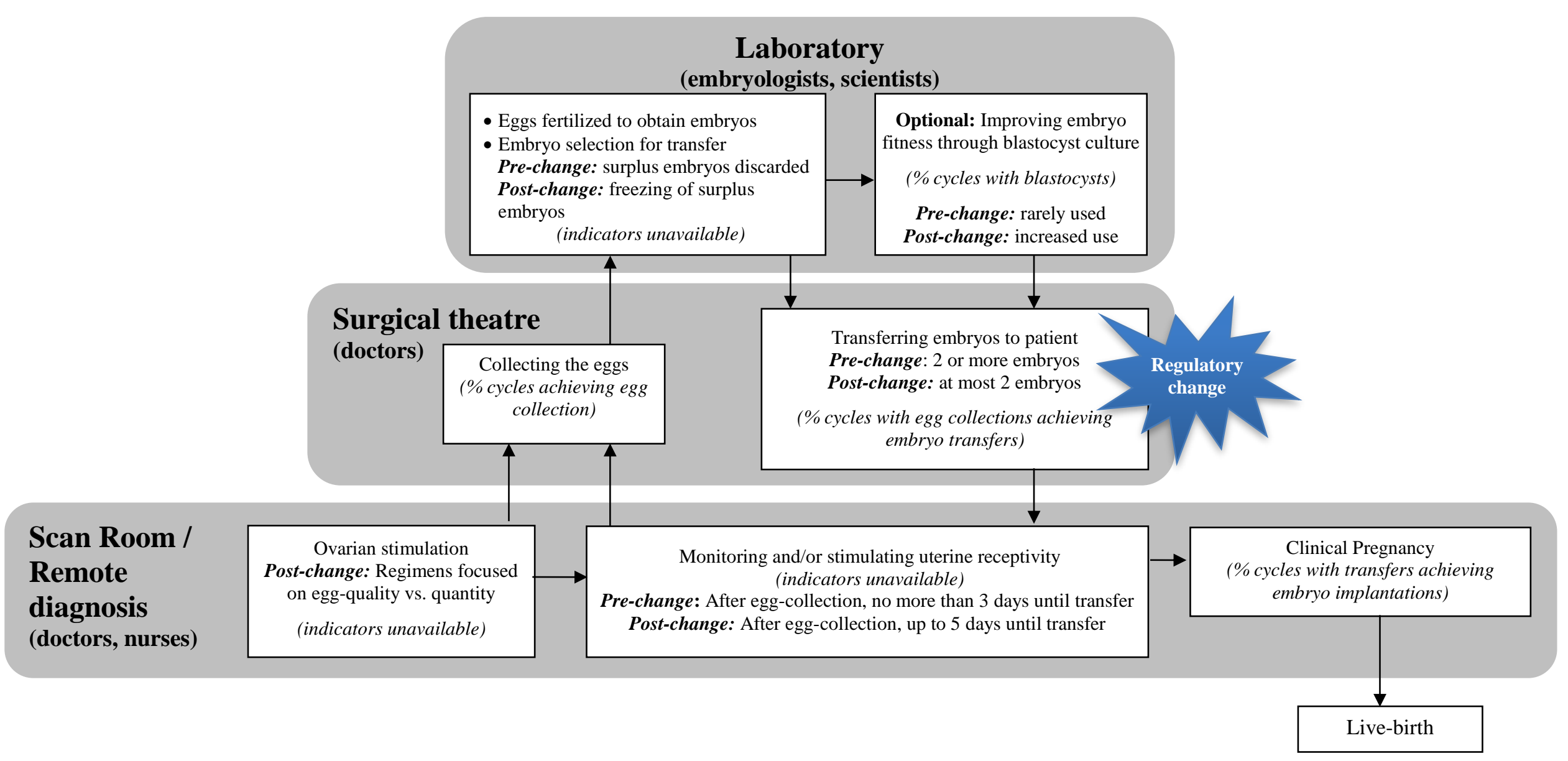

Figure 2. Intermediate steps in fertility treatments involving in vitro fertilization (IVF) 
Table 1. How fertility clinics handled changes to interdependence after the 2001 restriction on embryo transfers.

\begin{tabular}{|c|c|c|}
\hline & Before 2001 & After 2001 \\
\hline Interdependence & $\begin{array}{l}\text { Simpler patient pathways: "Before the first restriction on embryo transfers, things } \\
\text { were done in the old-fashioned way. The patient trajectories were clear and much } \\
\text { simpler than today, with less invasiveness in labs and less temperance about how } \\
\text { many embryos to transfer. "Doctor, Hackney } \\
\text { Steady patterns of interdependence: "The } 90 \text { s [pre-change] were all about } \\
\text { achieving fertilization, getting enough eggs, perfecting ICSI [invasive fertilization } \\
\text { procedure], and doing all we can to get the embryos. After refining these tasks in the } \\
\text { early } 90 \text { s, the treatment stages became predictable, easy to assess, compare and } \\
\text { organize... especially the stages leading to fertilization." Doctor, Aberdeen }\end{array}$ & $\begin{array}{l}\text { Unknown interdependencies: "We were tying to get ISO certified, but it was wild. It took us a while to } \\
\text { understand how to stabilize our processes after fiddling with the embryo transfer procedure and the tasks } \\
\text { leading up to it. We were uncertain what it all meant for us and our patients." Nurse, London } \\
\text { "The state of things was ripe for confusion, with no definite guidelines about the right way to do it, and } \\
\text { significant distress for patients undergoing treatment at the time. And this was during a time when egg- } \\
\text { freezing and other ways to compensate for lower embryo counts at transfer were not yet fully developed." } \\
\text { Doctor, London } \\
\text { Shift in focus, ripple effects: "The HFEA regulation came after we laid the building blocks of the } 90 \text { s, after } \\
\text { we stabilized the paths to fertilization. From } 2001 \text {, a different emphasis began to make way: the focus turned } \\
\text { to embryo fitness, getting embryo biopsies right, finding ways to extend embryo culture in laboratories. But } \\
\text { we learned that these depend a lot on the quality of the first stages in the treatment, because what happens } \\
\text { during stimulation or egg collection has ripple effects later, for embryo fitness. In a way, were back to the } \\
\text { drawing board, trying to identify these ripple effects." Doctor, Aberdeen }\end{array}$ \\
\hline $\begin{array}{l}\text { Clinics without } \\
\text { integrators }\end{array}$ & $\begin{array}{l}\text { Patient handoffs handled in a Tayloristic fashion: "They might see me for the first } \\
\text { consultation, then they might see the junior doctor for a scan, a third doctor for egg } \\
\text { collection, and a fourth doctor for embryo transfer - it's possible. We tried to } \\
\text { streamline it as much as we could, but it didn't always work. People were on leave, } \\
\text { people were on study leaves, people went to conferences and meetings, so we had to } \\
\text { work around all that. Sometimes patients complained they saw a different doctor } \\
\text { every time - sorry, that's the way it works. I can't help you. If you want to see the } \\
\text { same doctor, then go to a clinic who offers this." Doctor, Hackney } \\
\text { Patient information encoded in data repositories: "Day-to-day appointments, like } \\
\text { dispensing drugs or taking a blood test would be handled by a member of the nursing } \\
\text { team or the doctor on-call; patient notes, tests and shift reports are carefully } \\
\text { reviewed and audited." Nurse, London } \\
\text { "Due to different working days and rota patterns of the staff, a new IT system had to } \\
\text { be put in place to record patient medical information and to allow for smooth transits } \\
\text { through treatment stages." Nurse, Ninewells }\end{array}$ & $\begin{array}{l}\text { Protocols updated to meet regulation, often without mitigating the effects: "We only allow single } \\
\text { embryo transfers in women under } 35 \text {-years of age. This change in the Code of Practice had to be } \\
\text { implemented - no questions asked. Everyone had to reduce the incidence of multiple births at their centre, } \\
\text { even if that meant a drop in the overall success rates. It was a necessary evil in order to deal with a greater } \\
\text { evil [i.e. multiple births]." Nurse, London } \\
\text { "My friend was also worried that they won't transfer more than two embryos back to her. But [her clinic] } \\
\text { provided embryo freezing and screening, and seemed to have a better equipped lab. My experience was } \\
\text { different (...) If we must have less quantity, why can't we have more quality?" Patient, London } \\
\text { New task interdependencies if aiming to increase viability of embryos: "Not all clinics can handle the } \\
\text { complexities of some procedures such as embryo screening, genetic diagnosis and close patient monitoring. } \\
\text { They are certainly for the benefit of patients treated under the new regulation, who want to make sure that } \\
\text { two embryos give equal chance to a pregnancy as three, but handling the intricacies of such technologies is } \\
\text { not easy, the atypical steps in the process have to be managed not only for the patient but also for the staff } \\
\text { involved." Doctor, London }\end{array}$ \\
\hline $\begin{array}{l}\text { Clinics with } \\
\text { integrators }\end{array}$ & $\begin{array}{l}\text { Improved communication with all those involved: "As a named nurse or dedicated } \\
\text { physician you represent the patient. You know the [other specialists] well, so you } \\
\text { communicate with them better. Also your patient has more trust in you, and you can } \\
\text { communicate better with her; you can say you've seen her before, so you can try this } \\
\text { now. And those little points are important things." Doctor, Hackney } \\
\text { Personalized care and better management of patient information: } \\
\text { "Seeing the physician each time is possible in clinics offering individualized care. } \\
\text { This way there is less information loss from one visit to the other." Doctor, Plymouth } \\
\text { "The coordination of the treatment would be done by the named nurse and any } \\
\text { questions would be directed to her over the course of treatment. If the nurse is } \\
\text { unsure then she would ask the doctor for further advice." Nurse, Swansea }\end{array}$ & $\begin{array}{l}\text { Integrators manage interdependencies between functional specialists: "We upgraded the lab, hired new } \\
\text { embryologists and had the nurses go through new training (...), everyone was learning and getting new } \\
\text { skills. It was exciting, but also a bit messy. We had many new pieces of knowledge to consider and few knew } \\
\text { how to glue them together. I think that's why having one doctor or nurse keeping track of what was going on } \\
\text { with each individual patient helps. It's a less messy process and things get done." Doctor, Bath } \\
\text { Integrators as conduits for tacit knowledge acquired in the new context: "When you know that only one } \\
\text { embryo can be transferred back to her, it is better to have someone walking through this labyrinth with the } \\
\text { patient, from the first visit, to the embryo transfer with the nurse. This way there are fewer loose ends to tie } \\
\text { up, there is less miscommunication in doing things and everyone is more confident in what they are doing." } \\
\text { Doctor, Hackney } \\
\text { "If I'm there for all her visits, phoning lab results, checking her drug prescriptions (...) then I know things } \\
\text { really well for her. If something is wrong, I go directly to the nurse who did the scan or the embryologist who } \\
\text { prepared her samples." Nurse, Birmingham }\end{array}$ \\
\hline
\end{tabular}


Table 2. Indicative quotations from interviews showing differences in how doctors and nurses perform the integrator role

\begin{tabular}{|c|c|}
\hline $\begin{array}{l}\text { Informal Authority } \\
\text { is higher for doctor-integrators than for nurse-integrators }\end{array}$ & $\begin{array}{l}\text { Lateral communication } \\
\text { is higher for nurse-integrators than for doctor-integrators }\end{array}$ \\
\hline $\begin{array}{l}\text { Nurses have limited prescribing powers } \\
\text { For me it feels like a double life, where as a nurse one chases up the } \\
\text { others like a doctor, but without the doctor's robe and without the } \\
\text { doctor's prescribing powers. (Nurse, interview 2) } \\
\text { Nurses are less forceful in their interactions } \\
\text { Unlike the doctors who do this job, I cannot use the thundering tone } \\
\text { on everyone. And I accepted that this is the way it is. The others can } \\
\text { pull the carpet out from underneath my feet at anytime and I must be } \\
\text { able to stand on my feet and carry the can to the next stop. (Nurse, } \\
\text { interview 2) } \\
\text { Nurses are more inhibited by protocols } \\
\text { Many clinics allow nurses to expand their role from general staffing } \\
\text { to the named nurse role, but they are still restricted by what the } \\
\text { managers and doctors will let us do and by the vicarious liability } \\
\text { aspect. I can see the risks from their point of view, because they are } \\
\text { still responsible for our actions, but it still doesn't make it any less } \\
\text { frustrating to navigate the bureaucratic maze. (Nurse, interview 3) } \\
\text { Doctors are responsible for the mistakes of others } \\
\text { I take the embryologist's word that they've performed the right } \\
\text { procedures in the right order and so forth. Now if they [the patient] } \\
\text { had no embryos following that, I must be the one to take } \\
\text { responsibility and explain what happened. (Doctor, interview 5) }\end{array}$ & $\begin{array}{l}\text { Doctors engage less in coaching behaviors } \\
\text { Perhaps I should, but I often don't provide coaching. Doctors are more } \\
\text { focused on the biological dysfunctionalities of the patient rather than the } \\
\text { patient as a whole or the other members of the team; you'd rather hand } \\
\text { the soft issues to the nurse than fill your plate with that as well. (Doctor, } \\
\text { interview 1) } \\
\text { Nurses are more able to translate technical terms } \\
\text { It's my impression that they [the nurse-integrators] approach this task } \\
\text { with a broader perspective. I think with doctors, they're more technical, } \\
\text { much more decision-making orientated. The named nurses, because of } \\
\text { their training, not so much. They are much more able to explain complex } \\
\text { issues in simpler terms. (Doctor, interview 4) } \\
\text { Doctors may lack soft skills in lateral communication } \\
\text { I would expect that if a mistake is made in the lab, or in the operating } \\
\text { theatre, or on the phone with the patient, a consultant handling the case } \\
\text { would generally be less versed in people skills than a named nurse. He } \\
\text { will know what to do, but much less how to say it to the others. } \\
\text { (Embryologist, interview } 6 \text { ) } \\
\text { Doctors may socialize less with the rest of the team } \\
\text { As a doctor, my shifts start and end at different times, so I don't come on } \\
\text { duty with anybody and I don't go off duty with anybody. I do see all of } \\
\text { them at various points in time, but I have fewer opportunities after work } \\
\text { to go for drinks or have off-the-record chats. (Doctor, interview } 5 \text { ) }\end{array}$ \\
\hline
\end{tabular}




\section{Table 3. Descriptive statistics and pairwise correlations}

\begin{tabular}{|c|c|c|c|c|c|c|c|c|c|c|c|c|c|c|c|c|c|c|c|c|}
\hline & $\begin{array}{l}\text { Level of analysis: } \\
\text { clinic-year }\end{array}$ & Obs. & Mean & $\begin{array}{l}\text { Std. } \\
\text { dev. }\end{array}$ & Min & Max & 1 & 2 & 3 & 4 & 5 & 6 & 7 & 8 & 9 & 10 & 11 & 12 & 13 & 14 \\
\hline 1. & Success rate per patient & 914 & 0.21 & 0.08 & 0 & 0.53 & - & & & & & & & & & & & & & \\
\hline 2. & Clinic size (hundred patients) & 914 & 3.30 & 2.59 & 0.01 & 14.67 & 0.31 & - & & & & & & & & & & & & \\
\hline 3. & Clinic age (years) & 914 & 8.94 & 5.04 & 1 & 26 & 0.34 & 0.47 & - & & & & & & & & & & & \\
\hline 4. & (Log) Industry experience & 914 & 11.48 & 1.01 & 8.56 & 12.53 & 0.41 & 0.16 & 0.62 & - & & & & & & & & & & \\
\hline 5. & (Log) Clinic experience & 914 & 6.71 & 1.79 & 0 & 9.48 & 0.38 & 0.63 & 0.77 & 0.56 & - & & & & & & & & & \\
\hline 6. & Post-change (binary) & 914 & 0.33 & 0.47 & 0 & 1 & 0.30 & 0.13 & 0.58 & 0.59 & 0.41 & - & & & & & & & & \\
\hline 7. & (Log) Post-change experience & 914 & 2.14 & 3.1 & 0 & 8.63 & 0.33 & 0.22 & 0.62 & 0.59 & 0.46 & 0.98 & - & & & & & & & \\
\hline 8. & (Log) Pre-change experience & 914 & 6.57 & 1.745 & 0 & 9.1 & 0.35 & 0.63 & 0.74 & 0.50 & 0.99 & 0.31 & 0.35 & - & & & & & & \\
\hline 9. & Complex cases (\% patients over 35 ) & 914 & 0.46 & 0.10 & 0 & 0.84 & 0.23 & 0.20 & 0.43 & 0.41 & 0.35 & 0.46 & 0.47 & 0.30 & - & & & & & \\
\hline 10. & Technology (\% ICSI) & 914 & 0.21 & 0.21 & 0 & 0.77 & 0.44 & 0.20 & 0.57 & 0.69 & 0.48 & 0.66 & 0.67 & 0.40 & 0.41 & - & & & & \\
\hline 11. & Integrator (binary) & 914 & 0.49 & - & 0 & 1 & 0.09 & -0.03 & -0.04 & 0.02 & -0.08 & 0.01 & 0.00 & -0.08 & 0.10 & -0.01 & - & & & \\
\hline 12. & Authority-integrator (doctor, binary) & 513 & 0.31 & - & 0 & 1 & 0.14 & -0.06 & -0.12 & 0.02 & -0.14 & 0.02 & 0.00 & -0.16 & 0.16 & 0.03 & 0.67 & - & & \\
\hline 13. & Communication-integrator (nurse, binary) & 513 & 0.09 & - & 0 & 1 & -0.03 & 0.28 & 0.26 & 0.00 & 0.25 & 0.00 & 0.05 & 0.26 & -0.15 & -0.01 & 0.31 & -0.21 & - & \\
\hline 14. & Integrator mix (binary) & 513 & 0.11 & - & 0 & 1 & -0.01 & -0.20 & -0.16 & -0.03 & -0.19 & -0.02 & -0.06 & -0.19 & 0.06 & -0.13 & 0.34 & -0.23 & -0.11 & - \\
\hline
\end{tabular}

Note: The analysis is a longitudinal examination of 70 clinics, with an average of 13.1 years of observation per clinic (min of 6 years; max of 15 years). 
Table 4. Organizational adaptation and learning: Regression results for clinic success rates as births/patient

\begin{tabular}{|c|c|c|c|c|c|c|c|c|c|c|c|c|c|}
\hline Variable & 1 & 2 & 3 & 4 & 5 & 6 & \begin{tabular}{|c|}
7 \\
Subsample: \\
Integrator mix \\
\end{tabular} & $\begin{array}{c}8 \\
\text { Subsample: } \\
\text { Single type }\end{array}$ & \begin{tabular}{|c|}
9 \\
Subsample: \\
No integrators \\
\end{tabular} & 10 & $\begin{array}{c}11 \\
\text { Subsample: } \\
\text { Integrator mix }\end{array}$ & $\begin{array}{c}12 \\
\text { Subsample: } \\
\text { Single type }\end{array}$ & $\begin{array}{c}13 \\
\text { Subsample: } \\
\text { No integrators }\end{array}$ \\
\hline Clinic size (per 100 patients) & $\begin{array}{l}-0.0001 \\
(0.956)\end{array}$ & $\begin{array}{l}-0.0001 \\
(0.955)\end{array}$ & $\begin{array}{l}-0.0005 \\
(0.813)\end{array}$ & $\begin{array}{l}0.0003 \\
(0.893)\end{array}$ & $\begin{array}{l}-0.0001 \\
(0.950)\end{array}$ & $\begin{array}{c}0.002 \\
(0.641)\end{array}$ & \begin{tabular}{|c|}
0.041 \\
$(0.037)$
\end{tabular} & $\begin{array}{c}0.001 \\
(0.851)\end{array}$ & $\begin{array}{l}0.0003 \\
(0.954)\end{array}$ & $\begin{array}{c}0.002 \\
(0.699)\end{array}$ & $\begin{array}{c}0.035 \\
(0.066)\end{array}$ & $\begin{array}{l}-0.001 \\
(0.792)\end{array}$ & $\begin{array}{l}-0.001 \\
(0.848)\end{array}$ \\
\hline Complex cases & $\begin{array}{l}-0.112 \\
(0.032)\end{array}$ & $\begin{array}{l}-0.109 \\
(0.036)\end{array}$ & $\begin{array}{l}-0.109 \\
(0.034)\end{array}$ & $\begin{array}{l}-0.112 \\
(0.034)\end{array}$ & $\begin{array}{l}-0.111 \\
(0.033)\end{array}$ & $\begin{array}{l}-0.156 \\
(0.008)\end{array}$ & $\begin{array}{l}-0.083 \\
(0.672)\end{array}$ & $\begin{array}{l}-0.227 \\
(0.007)\end{array}$ & $\begin{array}{l}-0.10 \\
(0.332)\end{array}$ & $\begin{array}{l}-0.153 \\
(0.010)\end{array}$ & $\begin{array}{l}-0.084 \\
(0.674)\end{array}$ & $\begin{array}{l}-0.234 \\
(0.005)\end{array}$ & $\begin{array}{l}-0.095 \\
(0.361)\end{array}$ \\
\hline Technology & $\begin{array}{c}0.050 \\
(0.028)\end{array}$ & $\begin{array}{c}0.045 \\
(0.051)\end{array}$ & $\begin{array}{c}0.047 \\
(0.048)\end{array}$ & $\begin{array}{c}0.041 \\
(0.089)\end{array}$ & $\begin{array}{c}0.043 \\
(0.085)\end{array}$ & $\begin{array}{c}0.064 \\
(0.071)\end{array}$ & $\begin{array}{l}-0.030 \\
(0.697)\end{array}$ & $\begin{array}{c}0.106 \\
(0.037)\end{array}$ & $\begin{array}{c}0.085 \\
(0.145)\end{array}$ & $\begin{array}{c}0.065 \\
(0.063)\end{array}$ & $\begin{array}{l}-0.036 \\
(0.591)\end{array}$ & $\begin{array}{c}0.096 \\
(0.064)\end{array}$ & $\begin{array}{c}0.070 \\
(0.245)\end{array}$ \\
\hline Clinic age & $\begin{array}{c}0.004 \\
(0.044)\end{array}$ & $\begin{array}{c}0.006 \\
(0.008)\end{array}$ & $\begin{array}{l}0.006 \\
(0.010)\end{array}$ & $\begin{array}{c}0.007 \\
(0.009)\end{array}$ & $\begin{array}{l}0.007 \\
(0.012)\end{array}$ & $\begin{array}{l}0.010 \\
(0.437)\end{array}$ & $\begin{array}{l}-0.045 \\
(0.099)\end{array}$ & $\begin{array}{l}0.0002 \\
(0.990)\end{array}$ & $\begin{array}{c}0.027 \\
(0.197)\end{array}$ & $\begin{array}{c}0.013 \\
(0.322)\end{array}$ & -0.062 & $\begin{array}{l}0.004 \\
0.817)\end{array}$ & 0.038 \\
\hline (Log) Industry experience & $\begin{array}{c}0.006 \\
(0.327)\end{array}$ & $\begin{array}{c}0.001 \\
(0.897)\end{array}$ & $\begin{array}{c}0.001 \\
(0.846)\end{array}$ & $\begin{array}{l}-0.002 \\
(0.794)\end{array}$ & $\begin{array}{l}-0.001 \\
(0.857)\end{array}$ & $\begin{array}{l}-0.046 \\
(0.694)\end{array}$ & $\begin{array}{c}0.316 \\
(0.182)\end{array}$ & $\begin{array}{c}0.042 \\
(0.814)\end{array}$ & $\begin{array}{c}-0.20 \\
(0.283)\end{array}$ & $\begin{array}{l}-0.090 \\
(0.463)\end{array}$ & $\begin{array}{c}0.482 \\
(0.073)\end{array}$ & $\begin{array}{l}-0.004 \\
(0.983)\end{array}$ & $\begin{array}{l}-0.299 \\
(0.126)\end{array}$ \\
\hline (Log) Clinic experience & $\begin{array}{c}0.007 \\
(0.088)\end{array}$ & $\begin{array}{c}0.007 \\
(0.087)\end{array}$ & $\begin{array}{l}0.007 \\
(0.081)\end{array}$ & - & - & $\begin{array}{l}0.0003 \\
(0.946)\end{array}$ & $\begin{array}{l}-0.003 \\
(0.350)\end{array}$ & $\begin{array}{l}0.013 \\
(0.086)\end{array}$ & $\begin{array}{l}-0.006 \\
(0.370)\end{array}$ & - & - & - & - \\
\hline $\begin{array}{l}\text { (Log) Post-change clinic } \\
\text { experience }\end{array}$ & - & - & - & $\begin{array}{l}-0.002 \\
(0.172)\end{array}$ & $\begin{array}{l}-0.003 \\
(0.051)\end{array}$ & - & - & - & - & $\begin{array}{l}-0.002 \\
(0.288)\end{array}$ & $\begin{array}{c}0.012 \\
(0.027)\end{array}$ & $\begin{array}{c}0.001 \\
(0.675)\end{array}$ & $\begin{array}{l}-0.004 \\
(0.041)\end{array}$ \\
\hline $\begin{array}{l}\text { (Log) Pre-change clinic } \\
\text { experience }\end{array}$ & - & - & - & $\begin{array}{c}0.007 \\
(0.075)\end{array}$ & $\begin{array}{c}0.007 \\
(0.070)\end{array}$ & - & - & - & - & $\begin{array}{c}0.003 \\
(0.493)\end{array}$ & $\begin{array}{l}-0.004 \\
(0.354)\end{array}$ & $\begin{array}{c}0.010 \\
(0.308)\end{array}$ & $\begin{array}{c}0.005 \\
(0.171)\end{array}$ \\
\hline Post-change & - & $\begin{array}{l}-0.013 \\
(0.087)\end{array}$ & $\begin{array}{l}-0.024 \\
(0.023)\end{array}$ & - & - & $\begin{array}{l}-0.017 \\
(0.137)\end{array}$ & $\begin{array}{c}0.075 \\
(0.009)\end{array}$ & $\begin{array}{l}-0.007 \\
(0.704)\end{array}$ & $\begin{array}{l}-0.02 \\
(0.065)\end{array}$ & - & - & - & - \\
\hline Integrator $X$ Post-change & - & - & $\begin{array}{c}0.021 \\
(0.071)\end{array}$ & - & - & - & - & - & - & - & - & - & - \\
\hline Integrator mix $X$ Post-change & - & - & - & - & - & $\begin{array}{c}0.040 \\
(0.039)\end{array}$ & - & - & - & - & - & - & - \\
\hline $\begin{array}{l}\text { Authority-integrator (doctor) } \\
X \text { Post-change }\end{array}$ & - & - & - & - & - & $\begin{array}{l}0.017 \\
(0.202)\end{array}$ & - & - & - & - & - & - & - \\
\hline $\begin{array}{l}\text { Communication-integrator } \\
\text { (nurse) } \\
X \text { Post-change } \\
\end{array}$ & - & - & - & - & - & $\begin{array}{l}0.024 \\
(0.100) \\
\end{array}$ & - & - & - & - & - & - & - \\
\hline $\begin{array}{l}\text { Integrator } \\
X \text { Post-change clinic experience }\end{array}$ & - & - & - & - & $\begin{array}{c}0.003 \\
(0.063)\end{array}$ & - & - & - & - & - & - & - & - \\
\hline $\begin{array}{l}\text { Integrator mix } \\
X \text { Post-change clinic experience }\end{array}$ & - & - & - & - & - & - & - & - & - & $\begin{array}{c}0.005 \\
(0.110)\end{array}$ & - & - & - \\
\hline $\begin{array}{l}\text { Authority-integrator (doctor) } \\
X \text { Post-change clinic experience }\end{array}$ & - & - & - & - & - & - & - & - & - & $\begin{array}{c}0.003 \\
(0.140)\end{array}$ & - & - & - \\
\hline $\begin{array}{l}\text { Communication-integrator } \\
\text { (nurse) } \\
X \text { Post-change clinic experience }\end{array}$ & - & - & - & - & - & - & - & - & - & $\begin{array}{c}0.003 \\
(0.081)\end{array}$ & - & - & - \\
\hline Clinic-years $\left(\mathrm{N}_{\mathrm{t}}\right)$ & 914 & $\begin{array}{r}914 \\
70\end{array}$ & $\begin{array}{r}914 \\
70\end{array}$ & 914 & 914 & $\begin{array}{c}513 \\
70\end{array}$ & $\begin{array}{c}54 \\
8\end{array}$ & 203 & $\begin{array}{c}256 \\
35\end{array}$ & $\begin{array}{c}513 \\
70\end{array}$ & $\begin{array}{c}54 \\
8\end{array}$ & 203 & $\begin{array}{c}256 \\
35\end{array}$ \\
\hline $\begin{array}{l}\text { Clinics (N) } \\
\text { Years }\end{array}$ & $\begin{array}{c}70 \\
1992-2006\end{array}$ & $1992-2006$ & $\begin{array}{c}70 \\
1992-2006\end{array}$ & $\begin{array}{c}70 \\
1992-2006\end{array}$ & $\begin{array}{c}70 \\
1992-2006\end{array}$ & $1998-2006$ & $\begin{array}{c}8 \\
1998-2006\end{array}$ & $1998-2006$ & $\begin{array}{c}35 \\
1998-2006\end{array}$ & $\begin{array}{c}70 \\
1992-2006\end{array}$ & $\begin{array}{c}8 \\
1998-2006\end{array}$ & $\begin{array}{c}27 \\
1998-2006\end{array}$ & $\begin{array}{c}35 \\
1998-2006\end{array}$ \\
\hline F statistic & $\begin{array}{c}31.72 \\
(0.000)\end{array}$ & $\begin{array}{c}28.10 \\
(0.000)\end{array}$ & $\begin{array}{c}26.55 \\
(0.000)\end{array}$ & $\begin{array}{c}27.30 \\
(0.000)\end{array}$ & $\begin{array}{c}25.63 \\
(0.000)\end{array}$ & $\begin{array}{c}3.66 \\
(0.000)\end{array}$ & $\begin{array}{l}139.26 \\
(0.000)\end{array}$ & $\begin{array}{c}4.03 \\
(0.004)\end{array}$ & $\begin{array}{c}1.68 \\
(0.147)\end{array}$ & $\begin{array}{c}3.40 \\
(0.001)\end{array}$ & $\begin{array}{c}3.52 \\
(0.060)\end{array}$ & $\begin{array}{c}3.05 \\
(0.018)\end{array}$ & $\begin{array}{c}3.98 \\
(0.003)\end{array}$ \\
\hline
\end{tabular}

Notes: P-values are in parentheses; robust standard errors, constant and clinic fixed effects included, not reported. The time invariant main effect for the integrator is captured as part of the clinic fixed effect. Model 3: A test of the linear combination $\beta$ shitt $+\beta$ interaction $=0$ fails to reject the hypothesis that the coefficients are different in absolute size $(\mathrm{p}-\mathrm{val}=0.769)$. 